\title{
Kinetics of Thrombopoiesis
}

\author{
LAurence A. Harker \\ From the Department of Medicine, University of Washington School of \\ Medicine, Seattle, Washington
}

A в S T R A C T Measurements of megakaryocyte number, volume, nuclear number, and cytoplasmic granulation were compared in animals with induced thrombocytosis, normal platelet counts, and induced thrombocytopenia for 4- and 10-day periods. Thrombopoiesis, as measured by megakaryocytic mass and ${ }^{35} \mathrm{~S}$ incorporation into platelets, appeared to be regulated by the demand for circulating platelets. In addition, two mechanisms were operative in the alteration of thrombopoiesis. The first mechanism involved the regulation of endomitosis in the immature megakaryocytes which in turn determined the subsequent volume of platelet-producing cytoplasm. The second mechanism regulated the number of megakaryocytes formed from the precursor, "stem cell," compartment.

\section{INTRODUCTION}

This study was designed to investigate the manner in which thrombopoiesis is altered in order to achieve homeostasis when there is either increased or decreased demand for circulating platelets. Megakaryocyte number, size, sulfate uptake, endomitosis, and morphology were compared in states of normal, suppressed, and stimulated thrombopoiesis.

\section{METHODS}

Normal male Sprague-Dawley rats weighing $250 \pm 25 \mathrm{~g}$ were used; hematocrits were $40 \pm 3 \%$, and platelet counts were $1.33 \pm 0.19 \times 10^{6} / \mu$ l. Platelet production was suppressed by platelet hypertransfusion to counts of approximately $3.5-5.0 \times 10^{\circ} \mu 1$, and was maintained over a 4- and 10-day period by daily infusions into the tail vein

Dr. L. A. Harker is an instructor at the Division of Hematology, University of Washington, Seattle, Wash.

Received for publication 31 August 1967 and in revised form 20 October 1967. of $0.5-1.5 \mathrm{ml}$ of freshly prepared concentrated platelets. The platelets were obtained from fresh, whole blood which was withdrawn each day by cardiac puncture from ether anesthetized Sprague-Dawley donor rats with $4 \%$ sodium-citrate anticoagulant (1 volume: 9 volumes of blood). Plastic equipment was used for all procedures. Platelet-rich plasma (PRP) was separated from the red cells by centrifuging the blood at $500 \mathrm{~g}$ for $10 \mathrm{~min}$. After adjusting the $\mathrm{pH}$ of the PRP to 6.5 with $0.15 \mathrm{M}$ citric acid, we obtained a platelet "button" by centrifugation at $1200 \mathrm{~g}$ for $18 \mathrm{~min}$. A concentrated platelet suspension was prepared for injection by gently resuspending the platelet button in $0.5-1 \mathrm{ml}$ of plasma. Approximately $85 \%$ of the platelets was estimated to remain in circulation after injection. Six control animals were injected with comparable numbers of platelets, two animals over a 4-day period, and four animals over a 10-day period with similarly prepared platelet suspension which was refrigerated for $24-48 \mathrm{hr}$ at $4^{\circ} \mathrm{C}$ to render the platelets nonviable. Platelet counts in the control animals returned to the preinjection level within $30 \mathrm{~min}$ after infusion of such stored platelets, which indicated rapid removal from the circulation.

We stimulated thrombopoiesis by lowering the platelet count to less than $20 \%$ of normal for a 4- and 10-day period by performing daily exchange transfusions under ether anesthesia with platelet-poor blood in amounts approximately three times the animal's blood volume (1). For this purpose an indwelling plastic catheter was placed in the right internal jugular vein and brought to the surface between the animal's shoulders. Catheter patency was maintained during the intervals between the exchanges with heparin-saline solution. We prepared platelet-poor blood from the blood remaining after platelet harvesting. To achieve further platelet depletion, we washed the red cells four more times with saline, centrifuging at $500 \mathrm{~g}$ for $10 \mathrm{~min}$, and the plasma was made virtually platelet-free by centrifuging at $5000 \mathrm{~g}$ for 20 $\min (1)$. Heparin, $0.1 \mathrm{mg} / \mathrm{ml}$, was added and then the citrate was removed by the addition of $1 \mathrm{ml}$ of $10 \%$ calcium gluconate $/ 40 \mathrm{ml}$. The reconstituted blood had a platelet count of less than $20,000 / \mu 1$ and hematocrit of 45 to $50 \%$. Six control animals were prepared by catheter placement but without exchange transfusion: two animals over a 4-day period, and four animals over a 10-day period. 
For platelet counting, we collected $0.5 \mathrm{ml}$ of blood from the tail vein through a 23-gauge disposable needle into a plastic syringe containing $0.01 \mathrm{ml}$ citrate-cocaine anticoagulant. ${ }^{1}$ Blood, obtained by pricking or cutting the tail, collected into EDTA, or in smaller volume, showed significant and variable clumping resulting in unreliable counts. The combination of citrate and cocaine, which produced a blood $\mathrm{pH}$ of 6.5 , prevented all clumping. Platelets were counted with an electronic particle counter ${ }^{2}$ by a modification of the method of Bull, Schneiderman, and Brecher (2). In this technic the blood is first placed in plastic tubes at approximately $45^{\circ}$ angle in order to permit the sedimentation of red cells before the supernatant platelet-rich plasma is sampled for counting. The whole blood platelet count is derived from the plasma count corrected for the hematocrit. Although minimal plasma forms when rat blood is sedimented, one can obtain adequate plasma samples by placing the sedimenting tubes open-end up and sampling from the top. To prevent evaporation the tubes are covered with plastic. ${ }^{3}$ Because appreciable platelet sedimentation occurs within the 1 st half $\mathrm{hr}$, we remixed the whole blood samples by inverting and reinverting the sedimenting tubes immediately before sampling. This mixed the platelets in the supernatant plasma but did not greatly disturb the plasma red cell interphase.

Employing these modifications, we obtained the mean platelet count on cardiac blood from 100 normal animals, $1.33 \pm 0.19 \times 10^{6} / \mu 1$. Platelet counts on tail vein blood from the same animals agreed within $5 \%$ and the mean value was $1.29 \pm 0.20 \times 10^{6}$ platelets $/ \mu 1$. A hematocrit correction chart was constructed from platelet counts obtained from the electronic counter and phase microscopy (3) on the same animals. Values obtained could be superimposed on the curve reported for human blood (Fig. 1) by Bull et al. (2).

The total number of megakaryocytes was determined by an isotope-dilution method modified for tissue section sampling as previously described (4). A "multiple counting" error, due to counting the same cell in several adjacent sections is inherent in this method and varies with the megakaryocyte diameter. The factor for normal rat megakaryocytes is 7.0. The larger the diameter, however, the more frequently a single cell is counted and vice versa (4). Serial section studies of suppressed and stimulated marrows demonstrated the average number of cuts per cell to be 5.7 for 4-day suppression, 5.9 for 10-day suppression, 9.0 for 4-day stimulation, and 8.8 for 10-day stimulation, which reflected the change in cell size. The per cent ${ }^{50} \mathrm{Fe}$ skeletal localization at the time of sampling was determined for each animal studied by di-

$140 \mathrm{~g}$ of $\mathrm{Na}^{3}$-citrate, $13 \mathrm{~g}$ of citric acid made to $100 \mathrm{ml}$ with distilled water, $50 \mathrm{mg}$ of cocaine was added to each milliliter shortly before use.

${ }^{2}$ Coulter Electronic Counter, Hialeah, Fla. Model B transistorized preamplifier. Settings : aperture current $3 / 8$; amplification $1 / 4$; variable gain 90 ; matching switch $32 \mathrm{~L}$; $50 \mu$ aperture tube.

${ }^{3}$ Parafilm. American Can Company, Neenah, Wis.

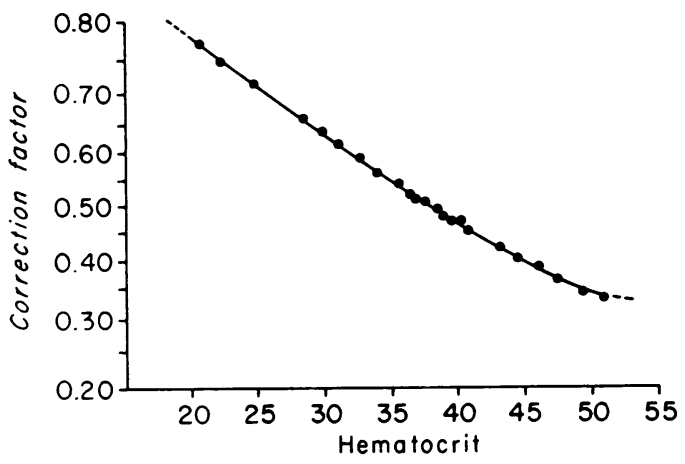

Figure 1 The whole blood platelet count is derived from the plasma platelet count by using a correction factor which is related to the hematocrit. The points were obtained by performing platelet counts with both electronic particle counting and phase microscopic chamber counting in rats. The solid line represents comparable determinations in man as reported by Bull et al. (2).

rect measurement of the radioactivity of the cleaned skeleton and the values were $33 \pm 3 \%$ of the injected dose.

Mean megakaryocyte diameter for each state of production was obtained from planimetry measurements of at least 300 megakaryocytes on marrow photomicrographs (4). Assuming a spheroidal shape of megakaryocytes (4), we calculated mean megakaryocyte volume from the diameter measurements. Total megakaryocytic volume ("megakaryocyte mass") represented the product of the mean megakaryocytic volume and total megakaryocyte number. We determined the ratio between cytoplasmic and nuclear volume from all serial section photomicrographs of 50 megakaryocytes each in normal, suppressed, and stimulated thrombopoiesis by cutting out nuclear and cytoplasmic portions of each cell and comparing the relative weights of uniform photographic paper.

From aceto-carmine-fixed 4 marrow "squash" preparation (5), the number of nuclei per cell was determined by oil immersion phase microscopy in at least 150 megakaryocytes from each animal studied. After the marrow was fixed for $2 \mathrm{hr}$, squash material was prepared on slides coated with $5 \%$ gelatin, and rimmed with liquid paraffin. Because megakaryocyte nuclear replication is synchronous (3-7), the expected nuclear count would be $2,4,8,16$, or 32 . Accordingly, on the basis of the estimated number of nuclei, the cells were classified as containing $2,4,8,16$, or 32 nuclei. When the number of nuclei fell between these values, the cell was grouped with the next highest class. The megakaryocytes were also classified morphologically from paint brush smears similar to Types I, II, and III designated by Feinendegen, Odartchenko, Cottier, and Bond (8) and Ebbe and Stohlman (9), where cytoplasmic azurophilic granulation was

4 Aceto-carmine fix was prepared by boiling $2 \mathrm{~g}$ of carmine in $100 \mathrm{ml}$ of $45 \%$ acetic acid for 1 to $2 \mathrm{hr}$. 
used as the indicator of maturation (Type I, no granulation; Type II, partial granulation; Type III, complete granulation). Bare nuclei were classified as Type IV.

Incorporation of ${ }^{36} \mathrm{~S}$ into the mucopolysaccharides of platelets $(10,11)$ was determined in the following way. After the 4-day period of platelet manipulation, 10 animals each for suppressed, normal, and stimulated thrombopoiesis were injected via the tail vein with a known dose of $\mathrm{Na}_{2}{ }^{36} \mathrm{SO}_{4}$ approximating $1 \mu \mathrm{c} / \mathrm{g}$ of body weight in a saline solution of less than $0.3 \mathrm{ml}$. No further exchange transfusions or platelet injections were carried out after the injection of ${ }^{25} \mathrm{~S}$. 3 days later the animal's weight and platelet count were determined following which $7 \mathrm{ml}$ of blood was withdrawn from the aorta into $1 \mathrm{ml}$ of acid citrate dextrose (ACD)..$^{5}$ Platelet-rich plasma was separated and adjusted to a $\mathrm{pH}$ of 6.5 with $0.15 \mathrm{M}$ citric acid. Subsequently, the platelets were centrifuged, $1200 \mathrm{~g}$ for $18 \mathrm{~min}$, and the supernatant decanted. After the platelet "button" was washed twice with normal platelet-free rat plasma, the platelets were resuspended in $0.5 \mathrm{ml}$ of normal plataelet-free rat plasma (containing $\mathrm{ACD} ; \mathrm{pH}$ adjusted with $0.15 \mathrm{M}$ citric acid to 6.5). The platelets in this concentrate were counted, and duplicate $200-\mu 1$ samples were solubilized in $0.5 \mathrm{ml}$ Hyamine. ${ }^{6}$ By phase microscopic examination, platelet clumping was shown to be absent and the ratio of platelets to white cells was over 2 million to 1 . We determined ${ }^{85} \mathrm{~S}$ activity in the samples and standards by liquid scintillation spectrometry ${ }^{7}$ using $10 \mathrm{ml}$ of a standard composition phosphor, ${ }^{8}$ and employing an internal standard correction for quenching. We calculated the total ${ }^{35} \mathrm{~S}$ platelet activity of the animal by multiplying the individual platelet radioactivity by the total body platelets (platelet count times blood volume). The per cent ${ }^{35} \mathrm{~S}$ incorporation into platelets represented the total ${ }^{25} \mathrm{~S}$ platelet activity of the animal over the ${ }^{85} \mathrm{~S}$ activity injected multiplied by 100 .

A blood volume of $6 \%$ of body weight was assumed in the calculations and this value was confirmed by ${ }^{51} \mathrm{Cr}$-labeled red cell measurements in 10 normal, $250 \mathrm{~g}$ animals. This blood volume factor was shown to be valid at the time of sacrifice in animals subjected to both platelet hypertransfusion and exchange transfusions.

\section{RESULTS}

The platelet levels induced in the three groups of animals studied are shown in Fig. 2 and similar changes were seen with animals studied for 10 days; induced thrombocytosis was maintained at $3.5-7.0 \times 10^{8} / \mu 1$ and thrombocytopenia remained

${ }^{5}$ NIH formula A.

${ }^{6}$ Hyamine, Packard Instrument Co.,' Downers Grove, III.

${ }^{7}$ Liquid Scintillation Spectrometer (Tri-Carb, Packard).

$81000 \mathrm{ml}$ of p-dioxane (spectrometry grade), $7 \mathrm{~g}$ of 2,5-diphenyloxazole, $0.3 \mathrm{~g}$ of 1,4-bis[2-(5-phenyloxazolyl)] benzene, $175 \mathrm{~g}$ of naphthalene.

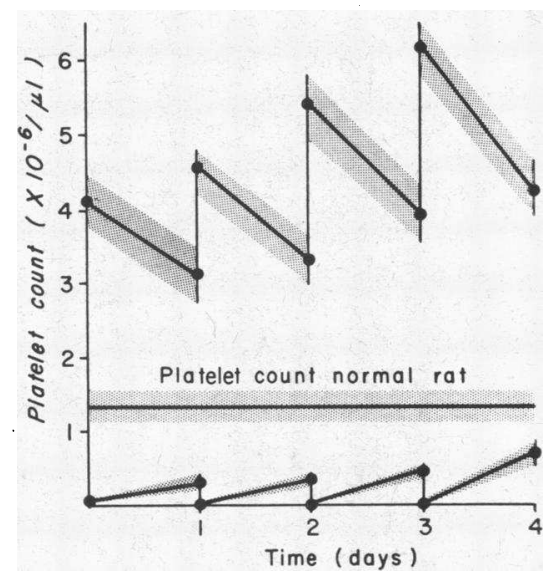

FIGURE 2 Changes in the circulating platelet counts achieved by daily platelet hypertransfusion, and daily exchange transfusions with platelet-poor blood, are compared with the normal platelet count in rats. Each point is the mean value from six animals and the shaded area represents 1 SD from the mean.

below $0.5 \times 10^{6} / \mu 1$. The degree of thrombocytosis achieved by platelet hypertransfusion was sustained at about three times the normal platelet count, and the thrombocytopenia produced by exchange transfusion of platelet-poor blood was maintained at an average of about $20 \%$ of the normal platelet level. The changes achieved in the megakaryocyte population of the marrow as the result of these manipulations were related to megakaryocyte size and number as shown in Fig. 3. It was assumed that these changes occurred in response to the manipulation of the platelet count because no significant alteration was demonstrable in megakaryocyte number, volume, or the pattern of nuclear number in the animals transfused with comparable numbers of nonviable platelets or in the control-operated animals.

The number of megakaryocytes in animals with suppressed and stimulated thrombopoiesis was significantly different from normal $(P<0.05)$ after 4 days of altered demand, and the differences were further increased after 10 days $(P<0.01)$. As shown in Table I, a greater than 8-fold difference in megakaryocyte number is apparent between the 10-day-suppressed and 10-day-stimulated groups. It is important to note that the numbers as expressed are corrected for the change in multiple counting error associated with megakaryocytes differing in diameter from the normal. The mean diameters of megakaryocytes in sup- 

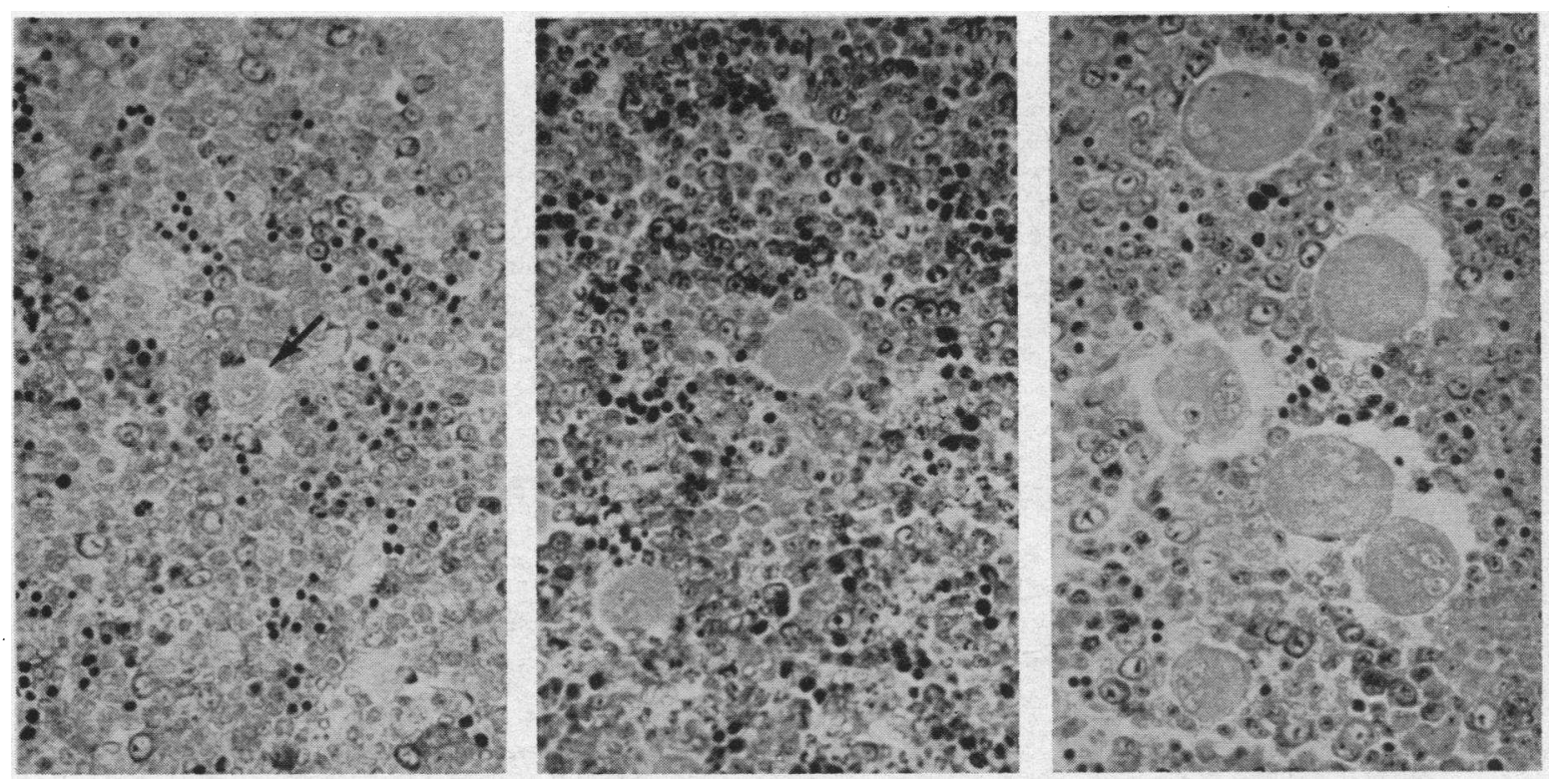

FIGURE 3 Comparative photomicrographs of representative bone marrow sections from animals with normal (center panel), suppressed (left panel), and stimulated (right panel) thrombopoiesis taken at a magnification of 320 . The change in size and number of megakaryocytes is apparent.

pressed and stimulated thrombopoiesis were also significantly different from normal (Table II) at the $1 \%$ level. At 4 days of study a $25-30 \%$ change in diameter had occurred and this size was maintained essentially without alteration during more prolonged stimulation or suppression. The mean volume of megakaryocytes calculated from the diameter measurements indicates a 4-fold difference between mean cell volume of suppressed and stimulated states of production. ${ }^{\circ}$

\begin{tabular}{l} 
9 Inasmuch as shrinkage occurred with Zenker's fixa- \\
tion, the megakaryocyte diameters and the resultant vol- \\
ume calculations have relative value only and are not \\
absolute measurements of cell volumes. \\
TABLE I \\
Megakaryocyte No. \\
\hline Mean megakaryocyte No. \\
Thrombopoiesis \\
Normal \\
4-day suppressed \\
10-day suppressed \\
4-day stimulated \\
10-day stimulated
\end{tabular}

* Values given represent the mean of six animals and have been corrected for the error of "multiple counting," appropriate for the mean diameter measurements.
We determined the total megakaryocyte mass ${ }^{10}$ for each state of production by multiplying the mean megakaryocyte number by the mean megakaryocyte volume (Table III). Since platelets are the product of megakaryocyte cytoplasm, estimates of cytoplasmic volume should be a measure

10 The term "mass" is used as currently applied in hematology, referring to the total megakaryocyte volume of all megakaryocytes and does not imply density measurements.

TABLE II

Megakaryocytic Size*

\begin{tabular}{ccc}
\hline Thrombopoiesis & Diameter & $\begin{array}{c}\text { Mean } \\
\text { megakaryocytic } \\
\text { volume }\end{array}$ \\
\hline Normal & $\mu \pm \mathrm{sD}$ & $\mu^{3}$ \\
4-day suppressed & $20.6 \pm 3.4$ & 4580 \\
10-day suppressed & $16.7 \pm 2.0$ & 2440 \\
4-day stimulated & $26.4 \pm 2.2$ & 2760 \\
10-day stimulated & $25.9 \pm 4.9$ & 9740 \\
& & 9100 \\
\hline
\end{tabular}

* Each mean value is based on a total of at least 250 diameter measurements from six animals. These values represent measurements from tissue fixed in Zenker's formaldehyde fixative with consequent shrinkage and therefore have relative significance only. Studies with glutaraldehyde-fixed material gave approximately $25 \%$ greater diameter measurements. 
TABLE III

Total Megakaryocyte Mass*

\begin{tabular}{|c|c|c|c|}
\hline Thrombopoiesis & $\begin{array}{c}\text { Mean mega- } \\
\text { karyocyte } \\
\text { No. }\end{array}$ & $\begin{array}{l}\text { Mean mega- } \\
\text { karyocyte } \\
\text { volume }\end{array}$ & $\begin{array}{l}\text { Total mega. } \\
\text { mass }\end{array}$ \\
\hline & $\times 10^{6} \mathrm{cells} / \mathrm{kg}$ & $\mu^{3}$ & $\mu^{3} \times 10^{10 / k g}$ \\
\hline Normal & 11.0 & 4580 & 5.0 \\
\hline 4-day suppressed & 7.0 & 2440 & 1.7 \\
\hline 10-day suppressed & 4.6 & 2760 & 1.3 \\
\hline 4-day stimulated & 15.1 & 9740) & 14.7 \\
\hline 10-day stimulated & 36.7 & 9100 & 33.4 \\
\hline
\end{tabular}

* Each value represents the mean of six animals.

of platelet production. Accordingly, the cytoplasm : nucleus ratio was determined in suppressed, normal, and stimulated thrombopoiesis. The values obtained were $4.0 \pm 0.4,3.8 \pm 0.4$, and $3.7 \pm 0.3$, respectively. Thus, the total cytoplasmic volume was calculated to be $4.0,1.4$, and $11.6 \times 10^{10}$ $\mu^{3} / \mathrm{kg}$ body weight in normal, 4-day-suppressed and 4-day-stimulated thrombopoiesis, respectively (Table IV).

Measurements of per cent ${ }^{35} \mathrm{~S}$ incorporation into platelets of normal, 4-day-suppressed, and 4-day-stimulated thrombopoiesis (Table IV) correlated with the corresponding estimates of cytoplasmic volumes (Fig. 4).

To investigate the nature of the megakaryocyte volume changes we estimated the nuclear number for each state of production (Table V). The nuclear distribution pattern was maximally shifted at 4 days and maintained after 10 days of altered thrombopoiesis. The number of nuclei per cell was rlecreased during suppressed thrombopoiesis

TABLE IV

${ }^{35} \mathrm{~S}$ S Platelet Incorporation in Altered Thrombopoiesis

\begin{tabular}{lcc}
\hline Thrombopoiesis & $\begin{array}{c}\text { Total cytoplasmic } \\
\text { volume of } \\
\text { megakaryocytes* }\end{array}$ & 35S in platelets + \\
\hline Normal & $\mu^{3} \times 10^{10} / \mathrm{kg}$ & $\% \times 10^{-2} \pm \mathrm{SD}$ \\
4-day suppressed & 4.0 & $1.18 \pm 0.19$ \\
4-day stimulated & 1.4 & $0.45 \pm 0.13$ \\
& 11.6 & $3.45 \pm 1.25$ \\
\hline
\end{tabular}

* Determined by multiplying the total megakaryocytic volume for normal, 4-day suppression, and 4-day stimulation by the portion of the megakaryocyte that is cytoplasmic $(0.79,0.79$, and 0.80 , respectively).

$\ddagger$ Each value for ${ }^{35} \mathrm{~S}$ incorporation represents the mean of 10 animals.

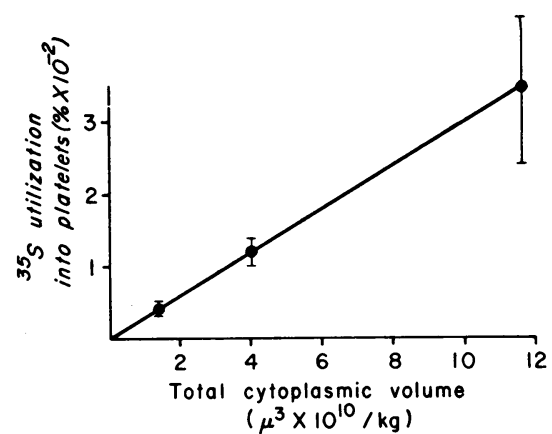

Figure 4 Per cent ${ }^{35} \mathrm{~S}$ incorporation into platelets is related to total megakaryocytic cytoplasmic volume in normal, 4-day-suppressed, and 4-day-stimulated thrombopoiesis. Each point represents the mean value from 10 animals and $1 \mathrm{SD}$ from the mean is shown.

and increased during stimulated production. The parallel relationship between megakaryocyte size and nuclear number was more apparent when a megakaryocyte diameter distribution curve was constructed (Fig. 5). Rather than showing a unimodal distribution, the curves appeared as multiple peaks which were shifted with altered thrombopoiesis in a fashion similar to changes in the pattern of nuclear number (Table V). Table VI shows the constant relationship between nuclear number and cytoplasmic volume by relating the nuclear number to the corresponding estimate of megakaryocyte cytoplasmic volume (based on peak diameter values from Fig. 5).

Cytoplasmic granulation was not significantly changed after 4 days of altered thrombopoiesis, but after 10 days the fraction of cells showing fully granulated cytoplasm significantly increased $(P<$

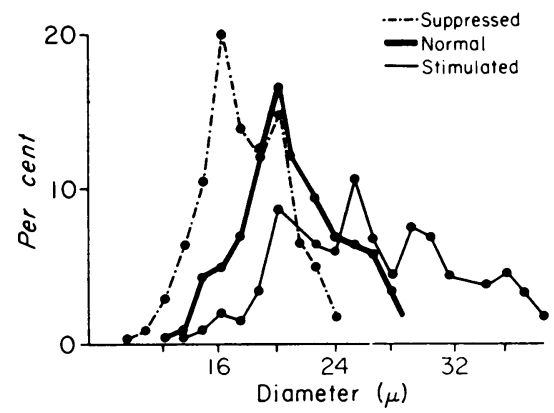

FIgURE 5 The distribution patterns of megakaryocyte diameter in normal, 4-day-suppressed, and 4-day-stimulated thrombopoiesis are multipeaked, with superimposition of specific megakaryocyte diameters in regions where the patterns overlap. 
TABLE V

Patterns of Nuclear Number*

\begin{tabular}{|c|c|c|c|c|c|}
\hline \multirow[b]{2}{*}{ Thrombopoiesis } & \multicolumn{5}{|c|}{ Distribution pattern of nuclear No. } \\
\hline & 2 & 4 & 8 & 16 & 32 \\
\hline & \multicolumn{5}{|c|}{$\% \pm \mathrm{SD}$} \\
\hline Normal & & $10.9 \pm 1.0$ & $70.0 \pm 2.0$ & $19.1 \pm 1.5$ & \\
\hline 4-day suppressed & $2.9 \pm 2.1$ & $51.7 \pm 3.1$ & $42.0 \pm 3.8$ & $3.4 \pm 2.1$ & \\
\hline 10-day suppressed & $2.6 \pm 2.0$ & $49.0 \pm 4.0$ & $45.4 \pm 4.2$ & $3.0 \pm 2.0$ & \\
\hline 4-day stimulated & & $1.0 \pm 1.2$ & $43.1 \pm 1.2$ & $51.8 \pm 1.2$ & $4.1 \pm 1.1$ \\
\hline 10-day stimulated & & $2.8 \pm 1.5$ & $47.0 \pm 2.5$ & $48.2 \pm 3.0$ & $2.0 \pm 2.0$ \\
\hline
\end{tabular}

* The nuclear No. was estimated in at least 150 megakaryocytes in each of six animals for each group.

0.05) with suppressed thrombopoiesis and decreased with stimulated thrombopoiesis (Table VII). Cytoplasmic granulation was observed in megakaryocytes with all numbers of nuclei, although cells with two nuclei showed granulation only in animals whose thrombopoiesis was suppressed.

\section{DISCUSSION}

Cells recognizable as megakaryocytes arise from as yet unidentified marrow precursor cells and are apparently incapable of maintaining the cell line $(7,9)$. The early phase of the megakaryocyte life cycle is characterized by nuclear proliferation which proceeds by endomitotic synchronous nuclear replication (5-7), so that the number of nuclei doubles with each mitotic episode. The maturation phase of the cell cycle which follows (12) is characterized by cytoplasmic accumulation and granulation (7-9). The ensuing cytoplasmic fragmentation into platelets $(7,13)$ leaves the residual "bare" nucleus which is processed by the reticuloendothelial system. The life cycle of the megakaryocyte extends over about 10 days in man (14) and about 4 days in the rat $(8,9)$. Thrombopoiesis

TABLE VI

Cytoplasmic Volume (CV) Related to Nuclear No.

\begin{tabular}{cccccc}
\hline \multicolumn{3}{c}{ Megakaryocyte } & & & \\
\cline { 1 - 3 } Diameter & Volume & $\mathrm{CV}^{*}$ & & No. of nuclei & CV/nucleus \\
\hline$\mu$ & $\mu^{3}$ & $\mu^{3}$ & & $\mu^{\mathbf{2}}$ \\
16 & 2150 & 1720 & 4 & 430 \\
20 & 4190 & 3350 & 8 & 420 \\
26 & 9200 & 7360 & 16 & 460 \\
\hline
\end{tabular}

* Calculated to be $80 \%$ of the total cell volume. appears to be regulated to meet the demand for circulating platelets (14), but few quantitative studies have been reported to test this thesis and the mechanisms of altered thrombopoiesis have not been defined.

In the present study, sustained thrombocytopenia evoked measured increases in thrombopoiesis as measured by megakaryocytic mass of three times normal at 4 days and over six times normal after 10 days (Table III). This increase was achieved by two separate mechanisms; the initial mechanism affected the volume of the individual megakaryocytes, and the later mechanism altered the number of megakaryocytes. With increase in cell size, there is a parallel increase in the number of nuclei (Table VI) ; the volume change thus appears to be the result of increased endomitotic nuclear replication.

In previously published studies of acutely stimulated thrombopoiesis $(1,15,16)$, modest increases in the number of megakaryocytes (25$30 \%$ ) have been reported based on marrow section counting. However, the number of megakaryocytes counted in tissues is directly related to both cell diameter and cell number (4). Consequently, an "apparent" increase of $25 \%$ in the number of megakaryocytes could reflect a $25 \%$ increase in cell diameter without an increase in cell number.

The additional increment in platelet production associated with prolonged stimulus was achieved by an increase in the rate of new megakaryocyte formation from the precursor pool as evidenced by a relative increase of immature cells compared to mature cells (Table VII) and an absolute increase in cell number (Table I). 
TABLE VII

Megakaryocyte Cytoplasm*

\begin{tabular}{crrrr}
\hline Thrombopoiesis & No granulation & Partial granulation & Full granulation & Bare nuclei \\
\hline & & \multicolumn{2}{c}{$\% \pm$ SD } & \\
Normal & $18.4 \pm 2.1$ & $24.9 \pm 2.6$ & $51.0 \pm 2.4$ & $6.7 \pm 1.8$ \\
4-day suppressed & $19.0 \pm 1.9$ & $23.8 \pm 2.0$ & $50.1 \pm 3.4$ & $7.1 \pm 3.0$ \\
10-day suppressed & $7.6 \pm 1.7$ & $23.7 \pm 2.1$ & $62.5 \pm 3.1$ & $6.2 \pm 1.4$ \\
4-day stimulated & $19.3 \pm 2.3$ & $26.0 \pm 2.0$ & $46.8 \pm 2.7$ & $7.9 \pm 1.9$ \\
10-day stimulated & $27.5 \pm 2.2$ & $37.1 \pm 2.8$ & $24.9 \pm 2.6$ & $10.5 \pm 3.1$ \\
\hline
\end{tabular}

* At least 100 megakaryocytes in each of six animals for each group were studied. Results are not significantly different at 4 days, but become significant $(P<0.05)$ at 10 days except for the bare nuclei.

Reciprocal changes were noted with suppressed thrombopoiesis. Initially, the decrease largely reflected diminished megakaryocyte volume (Table II) due to a decrease in endomitosis as indicated by parallel reduction in cell volume and nuclear number (Table VI). The further reduction in thrombopoiesis measured at 10 days was due to a decrease in cell formation from the precursor pool as indicated by a decreased number of megakaryocytes (Table I) and a shift to more cytologically mature cells (Table VII).

Data in other studies of acutely suppressed thrombopoiesis would appear to be consistent with these interpretations. Odell, Jackson, and Reiter's report that platelet hypertransfusion caused a 25$30 \%$ decrease in megakaryocytes counted in marrow sections (17) could be explained as a decrease in multiple counting associated with a $25 \%$ decrease in cell diameter without a change in the number of megakaryocytes. With DNA labeling and morphological analysis, Ebbe, Stohlman, Donovan, and Howard (18) found no evidence of a decreased rate of megakaryocyte formation from the precursor pool after acute transfusion-induced thrombocytosis.

The nuclei within a megakaryocyte form at an early stage when the cytoplasm is sparse and nongranulated (12). The number of nuclei formed is related to the demand for circulating platelets ( $\mathrm{Ta}$ ble V). The amount of platelet-producing cytoplasm that accumulates is directly correlated with the number of nuclei (Table VI). Thus, platelet production is determined indirectly by the same mechanism which regulates intracellular nuclear replication, i.e., endomitosis. The appearance of fully granulated, i.e. mature, megakaryocytes with only two nuclei in suppressed thrombopoiesis and nongranulated megakaryocytes with 16 nuclei in stimulated thrombopoiesis indicates the degree of ploidy per se is not the determining factor in cytoplasmic maturation. Maturation of the cytoplasm, as evaluated by the appearance of granulation, appeared not to be significantly altered after 4-day-stimulated or -suppressed thrombopoiesis (Table VII). The pattern of cytoplasmic maturation was observed, however, to be significantly modified after 10 days of altered platelet production and indicated either an unsteady state or a change in the rate of megakaryocyte maturation.

Because the data presented here show that the incorporation of ${ }^{35} \mathrm{~S}$ into platelets correlates with total cytoplasmic volume of megakaryocytes in suppressed, normal, and stimulated thrombopoiesis, this determination would seem to be useful as a measure of relative platelet production.

\section{ACKNOWLEDGMENTS}

The author gratefully acknowledges the helpful suggestions given by Dr. C. A. Finch during the course of the study, and wishes to thank both Dr. Finch and Dr. Eloise Giblett for their review of the manuscript. The technical assistance of Mrs. Barbara Cheney and Mrs. Loretta Willis was greatly appreciated.

This investigation was supported in part by $U$. S. Public Health Service research grant 5-RO1-HE-06242 and Fellowship Grant 1-F3-HE-32, 188-01.

\section{REFERENCES}

1. Matter, M., J. R. Hartmann, J. Kautz, Q. B. DeMarsh, and C. A. Finch. 1960. A study of thrombopoiesis in induced acute thrombocytopenia. Blood. 15: 174.

2. Bull, B. S., M. A. Schneiderman, and G. Brecher. 1965. Platelet counts with the Coulter counter. Am. J. Clin. Pathol. 44: 678.

3. Brecher, G., M. Schneiderman, and E. P. Cronkite. 
1953. The reproducibility and constancy of the platelet count. Am. J. Clin. Pathol. 23: 15.

4. Harker, L. A. 1968. Megakaryocyte quantitation. J. Clin. Invest. $47: 452$.

5. Japa, J. 1943. A study of the morphology and development of the megakaryocytes. Brit. J. Exptl. Pathol. 24: 73 .

6. Odell, T. T., Jr., C. W. Jackson, and D. G. Gosslee. 1965. Maturation of rat megakaryocytes studied by microspectrophotometric measurement of DNA. Proc. Soc. Exptl. Biol. Med. 119: 1194.

7. Kinosita, R., and S. Ohno. 1967. Biodynamics of thrombopoiesis. In Blood Platelets. Henry Ford Hospital International Symposium. 1960. S. A. Johnson, R. W. Monto, J. W. Rebuck, and R. C. Horn, Jr., editors. Little, Brown and Company, Boston. 611.

8. Feinendegen, L. E., N. Odartchenko, H. Cottier, and V. P. Bond. 1962. Kinetics of megacaryocyte proliferation. Proc. Soc. Exptl. Biol. Med. 111: 177.

9. Ebbe, S., and F. Stohlman, Jr. 1965. Megakaryocytopoiesis in the rat. Blood. 26: 20.

10. Odell, T. T., Jr., F. G. Tausche, and W. D. Gude. 1955. Uptake of radioactive sulfate by elements of the blood and bone marrow of rats. Am. J. Physiol. 180: 491.

11. Odell, T. T., Jr., and T. P. McDonald. 1964. Two mechanisms of sulfate- $\mathrm{S}^{35}$ uptake by blood platelets of rats. Am. J. Physiol. 206: 580.
12. Odell, T. T., Jr., and C. W. Jackson. Megakaryocyte maturation. 3rd Conference on Blood Platelets, June 1967. Oak Ridge, Tenn. 23. (Abstr.)

13. Yamada, E. 1957. The fine structure of the megakaryocyte in the mouse spleen. Acta Anat. 29: 267.

14. Cronkite, E. P., V. P. Bond, T. M. Fliedner, D. A. Paglia, and E. R. Adamik. 1961. Studies on the origin, production and destruction of platelets. In Blood Platelets. Henry Ford Hospital International Symposium. 1960. S. A. Johnson, R. W. Monto, J. W. Rebuck, and R. C. Horn, Jr., editors. Little, Brown and Company, Boston. 595.

15. Odell, T. T., Jr., T. P. McDonald, and M. Asano. 1962. Response of rat megakaryocytes and platelets to bleeding. Acta Haematol. 27: 171.

16. Craddock, C. G., W. S. Adams, S. Perry, and J. S. Lawrence. 1955. Dynamics of platelet production as studied by a depletion technique in normal and irradiated dogs. J. Lab. Clin. Med. 45: 906.

17. Odell, T. T., Jr., C. W. Jackson, and R. S. Reiter. 1967. Depression of the megakaryocyte-platelet system in rats by transfusion of platelets. Acta Haematol. 38: 34 .

18. Ebbe, S., F. Stohlman, Jr., J. Donovan, and D. Howard. 1966. Megakaryocytopoiesis in the rat with transfusion-induced thrombocytosis. Proc. Soc. Exptl. Biol. Med. 122: 1053. 